\title{
OSCILLATIONS CAUSED BY SEVERAL NON-MONOTONE DEVIATING ARGUMENTS
}

\author{
George E. Chatzarakis
}

\begin{abstract}
This paper presents new sufficient conditions, involving limsup and liminf, for the oscillation of all solutions of differential equations with several non-monotone deviating arguments and nonnegative coefficients. Corresponding differential equations of both delay and advanced type are studied. We illustrate the results and the improvement over other known oscillation criteria by examples, numerically solved in MATLAB.
\end{abstract}

Mathematics subject classification (2010): 34K11, 34K06.

Keywords and phrases: differential equation; non-monotone argument; oscillatory solution; nonoscillatory solution.

\section{REFERENCES}

[1] E. Braverman, G. E. Chatzarakis And I. P. Stavroulakis, Iterative oscillation tests for differential equations with several non-monotone arguments, Adv. Difference Equ., 2016, DOI 10.1186/s13662-016-0817-3, pages 18.

[2] E. BRAVERMAN AND B. KARPUZ, On oscillation of differential and difference equations with nonmonotone delays, Appl. Math. Comput., 218 (2011), 3880-3887.

[3] G. E. ChatZarakis, Differential equations with non-monotone arguments: Iterative Oscillation results, J. Math. Comput. Sci., 6, 5 (2016), 953-964.

[4] G. E. ChatZarakis AND H. PÉICS, Differential equations with several non-monotone arguments: An oscillation result, Appl. Math. Lett., 68 (2017), 20-26.

[5] L. H. Erbe, Qingkai Kong And B. G. Zhang, Oscillation Theory for Functional Differential Equations, Marcel Dekker, New York, 1995.

[6] L. H. ERBE AND B. G. ZhANG, Oscillation of first order linear differential equations with deviating arguments, Differential Integral Equations, 1 (1988), 305-314.

[7] N. FukAgai AND T. KusAno, Oscillation theory of first order functional-differential equations with deviating arguments, Ann. Mat. Pura Appl. 136 (1984), 95-117.

[8] B. R. Hunt ANd J. A. Yorke, When all solutions of $x^{\prime}(t)=-\sum q_{i}(t) x\left(t-T_{i}(t)\right)$ oscillate, J. Differential Equations 53 (1984), 139-145.

[9] J. JARoš AND I. P. StAVRoulaKis, Oscillation tests for delay equations, Rocky Mountain J. Math., 45 (2000), 2989-2997.

[10] M. Kon, Y. G. Sficas and I. P. Stavroulakis, Oscillation criteria for delay equations, Proc. Amer. Math. Soc., 128 (1994), 675-685.

[11] R. G. Koplatadze And T. A. ChanturiJa, Oscillating and monotone solutions of first-order differential equations with deviating argument, (Russian), Differentsial'nye Uravneniya 18 (1982), $1463-1465,1472$.

[12] R.G. Koplatadze And G. KViniKadze, On the oscillation of solutions of first order delay differential inequalities and equations, Georgian Math. J., 3 (1994), 675-685.

[13] T. KuSANO, On even-order functional-differential equations with advanced and retarded arguments, J. Differential Equations 45 (1982), 75-84.

[14] M. K. Kwong, Oscillation of first-order delay equations, J. Math. Anal. Appl. 156 (1991), 274-286. 
[15] G. LADAS, V. LAKShmiKANTHAM AND L. S. PAPADAKIS, Oscillations of higher-order retarded differential equations generated by the retarded arguments, Delay and Functional Differential Equations and their Applications, Academic Press, New York, 1972, 219-231.

[16] G. LadAS AND I. P. STAVROUlaKis, Oscillations caused by several retarded and advanced arguments, J. Differential Equations 44 (1982), 134-152.

[17] G. S. LADDE, Oscillations caused by retarded perturbations of first order linear ordinary differential equations, Atti Acad. Naz. Lincei Rendiconti 63 (1978), 351-359.

[18] G. S. Ladde, V. Lakshmikantham, B. G. Zhang, Oscillation Theory of Differential Equations with Deviating Arguments, Monographs and Textbooks in Pure and Applied Mathematics, vol. 110, Marcel Dekker, Inc., New York, 1987.

[19] X. LI AND D. ZHU, Oscillation and nonoscillation of advanced differential equations with variable coefficients, J. Math. Anal. Appl. 269 (2002), 462-488.

[20] A. D. MYshKIs, Linear homogeneous differential equations of first order with deviating arguments, Uspekhi Mat. Nauk 5 (1950), 160-162. (Russian)

[21] J. S. YU, Z. C. WANG, B. G. ZHANG AND X. Z. QIAN, Oscillations of differential equations with deviating arguments, Panamer. Math. J. 2, 2 (1992), 59-78.

[22] B. G. ZHANG, Oscillation of solutions of the first-order advanced type differential equations, Science exploration 2 (1982), 79-82.

[23] D. ZHOU, On some problems on oscillation of functional differential equations of first order, J. Shandong University 25 (1990), 434-442. 